\title{
Review
}

Journal of Innate

Immunity
J Innate Immun 2017;9:250-261

DOI: $10.1159 / 000455857$
Received: October 10, 2016

Accepted after revision: January 5, 2017

Published online: February 22, 2017

\section{Inflammation: A Double-Edged Sword in the Response to Pseudomonas aeruginosa Infection}

\author{
Christina K. Lin Barbara I. Kazmierczak \\ Yale University School of Medicine, New Haven, CT, USA
}

\section{Keywords}

Pseudomonas aeruginosa · Inflammation · Inflammasome .

Pneumonia $\cdot$ Innate immunity $\cdot$ Host defense

\begin{abstract}
The Gram-negative opportunistic pathogen Pseudomonas aeruginosa exploits failures of barrier defense and innate immunity to cause acute infections at a range of anatomic sites. We review the defense mechanisms that normally protect against $P$. aeruginosa pulmonary infection, as well as the bacterial products and activities that trigger their activation. Innate immune recognition of $P$. aeruginosa is critical for pathogen clearance; nonetheless, inflammation is also associated with pathogen persistence and poor host outcomes. We describe $P$. aeruginosa adaptations that improve this pathogen's fitness in the inflamed airway, and briefly discuss strategies to manipulate inflammation to benefit the host. Such adjunct therapies may become increasingly important in the treatment of acute and chronic infections caused by this multi-drug-resistant pathogen.
\end{abstract}

(c) 2017 S. Karger AG, Basel

\section{Introduction}

Pseudomonas aeruginosa, a ubiquitous environmental Gram-negative bacterium, is an opportunistic pathogen of immunocompromised and immunocompetent patients in whom wounds, burns, or foreign objects (i.e., central lines, catheters, and ventilators) disrupt epithelial barriers to infection. Patients with an altered lung architecture, including those with cystic fibrosis (CF), chronic obstructive pulmonary disease (COPD), bronchiectasis, or ventilator-associated pneumonia, are at particular risk for persistent $P$. aeruginosa colonization following an initial, acute infection. The intrinsic antimicrobial resistance of $P$. aeruginosa and strain-specific arrays of virulence factors also contribute to its pathogenesis [1-5].

Like other opportunists, $P$. aeruginosa does not possess multiple mechanisms that allow highly mammalianadapted pathogens to avoid or delay detection by the host immune system. Instead it triggers robust inflammatory responses during acute infection, which usually lead to pathogen clearance and resolution of infection. Paradoxically, the strong inflammatory responses to $P$. aeruginosa are often associated with bacterial persistence and tissue damage. We will review how $P$. aeruginosa activates the innate immune response and describe pathogen- and inflammation-mediated mechanisms of tissue damage, particularly in the lung (Fig. 1). We will highlight path-

Dr. Barbara I Kazmierczak

Yale University School of Medicine 333 Cedar St.

New Haven, CT 06520-8022 (USA)

E-Mail barbara.kazmierczak@yale.edu 
ways that might promote persistence and chronic infection in an environment of ongoing inflammation.

Most animal studies of $P$. aeruginosa pulmonary infection employ inbred mice, which provide genetic and analytic tools to allow characterization of host immune responses to this pathogen. Acute infection models introduce planktonic $P$. aeruginosa intranasally or intratracheally, while chronic infection models require inoculation of agar bead-embedded bacteria into the trachea [6]. One challenge in the field is the well-documented heterogeneity of $P$. aeruginosa strains, as even the commonly used laboratory strains vary in their expression of virulence factors and proinflammatory ligands - and clinical isolates have often undergone significant adaptations during prolonged periods of host colonization, as is observed in chronically infected CF patients $[7,8]$. Thus the observed immune responses of an infected mouse can vary between studies based on the specific bacterial strain that is employed, the dose of the inoculum and the time postinfection at which responses are measured [9], and the strain of mouse [10]. In general, however, lethal challenge of mice with $P$. aeruginosa results in septic shock and death appears to result from this hyperinflammatory response [11].

\section{Immune Recognition and Response to P. aeruginosa Infection}

\section{Crossing the Barrier: Local Defenses to P. aeruginosa} Acute Infection

$P$. aeruginosa pulmonary infection is preceded by the introduction of environmental bacteria into the upper respiratory tract. The resulting colonization establishes a population that can be aspirated, seeding the lower air-

Fig. 1. Responses of epithelial and immune cells to Pseudomonas aeruginosa. Trachea: Defenses of the tracheal pseudostratified epithelium. Mucociliary flow driven by ciliated tracheal epithelial cells is critical to bacterial clearance. Mucin contains secreted IgA, as well as antimicrobial peptides (AMP) and defensins whose production is induced by epithelial recognition of $P$. aeruginosa via multiple Toll-like receptors (TLR). Lipopolysaccharide and other pathogen-associated molecular patterns stimulate TLR2 and TLR4; basolateral TLR5 responds to flagellin; TLR9 mediates recognition of unmethylated CpG in bacterial DNA. Dendritic cells can sample bacterial antigens for subsequent presentation in the lymph nodes. Bacterially mediated damage to epithelial cells results in the release of IL-1 $\alpha$ and other alarmins, stimulating host inflammatory responses. Bronchiole: The interferon (IFN) response is differentially expressed between immune cells and epithelial cells. The type I IFN response has been shown to repress ways for infection. Barriers to infection include an airway mucus embedded with antimicrobial peptides secreted by epithelial and immune cells [reviewed in 12], as well as local immune responses by alveolar macrophages (AM), opsonization by secretory IgA, and antimicrobial activities of surfactant proteins, such as SP-A and SP-D, in the lower airways [13]. Most aspirated bacteria are trapped in mucus, carried upward by the action of airway cilia, and cleared by a robust cough reflex. Conditions that bypass (e.g., endotracheal intubation) or impair (e.g., CF) mucociliary clearance greatly favor $P$. aeruginosa colonization and infection of the airways.

$P$. aeruginosa employs several virulence factors to interact with and cross polarized epithelial cell monolayers. These include its single polar flagellum, which facilitates near-surface swimming and attachment, retractile type 4 pili, which power adhesion to and movement across biotic surfaces, and a type 3 secretion system (T3SS), which injects a subset of bacterial "effector" proteins into host cells. Paracellular transmigration of $P$. aeruginosa across an epithelium, perhaps preferentially at sites of cell division, senescence, or wounding, allows bacteria to spread along the basolateral surface of the monolayer [14, 15]. Subsequent T3SS-mediated intoxication of epithelial cells results in a variety of outcomes, depending on the specific complement of effectors expressed by a $P$. aeruginosa strain. These can include cell necrosis, mediated by the phospholipase $A_{2}$ activity of exoenzyme $U$ (ExoU), and disruption of epithelial integrity and viability, mediated by the GAP (GTPase activating protein) and ADPRT (ADP ribosyltransferase) activities of ExoS and ExoT [16-19]. The fourth definitive T3SS effector, the nucleotidyl cyclase ExoY, causes a similar disruption of endothelial cell barrier integrity [20].

IL- $1 \beta$-dependent recruitment of PMN. The type III IFN response results in increased production of the proinflammatory peptide PDCD4 and has been correlated with increased $P$. aeruginosa biofilm formation. Alveolus: Inflammasome-mediated recognition of $P$. aeruginosa. The innate immune response in the lower airways and alveoli (depicted) includes NLRC4 and NLRP3 inflammasome activation in alveolar macrophages, leading to production and secretion of proinflammatory IL- $1 \beta$ and IL-18. In addition to responding directly to bacterial products and actions, epithelial cells also amplify IL- $1 \beta$ signals, resulting in the release of CXC chemokines (IL-6, IL-8, and MIP-2). Recruited neutrophils aid in bacterial clearance via phagocytic killing and NETosis, but they also cause tissue damage and compromised gas-exchange in the lung. The anatomical location of insets depicted in the trachea, bronchiole, and alveolus is diagrammed at the bottom left.

(For figure see next page.)

J Innate Immun 2017;9:250-261

DOI: $10.1159 / 000455857$ 


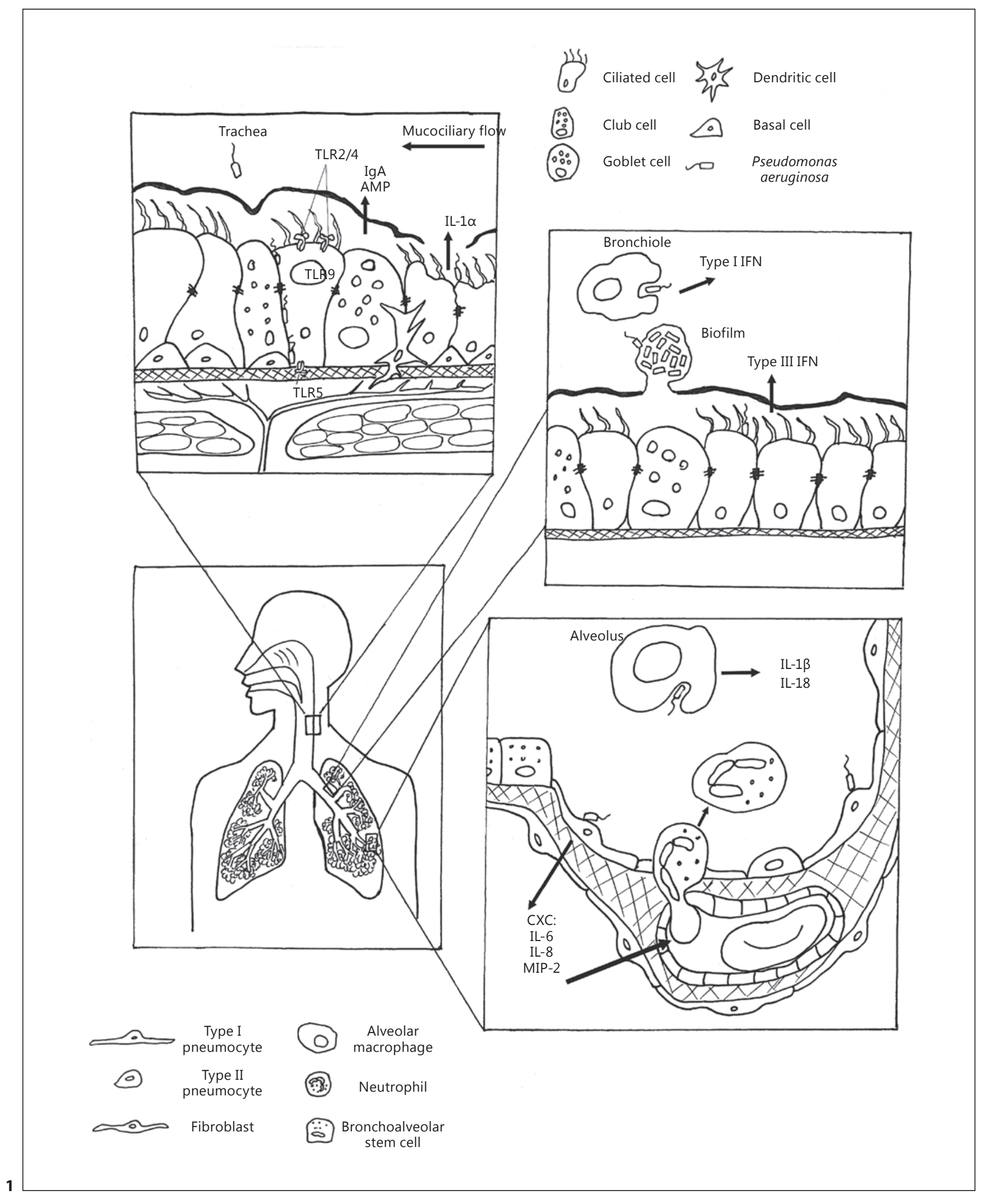


Extracellular $P$. aeruginosa is recognized by multiple mechanisms that will be discussed below. However, bacterially mediated cell injury and death also activate cellintrinsic pathways in immune and nonimmune cells, particularly those involving NF- $\mathrm{BB}$ and mitogen-activated protein kinase. For example, attachment of $P$. aeruginosa pili to the apical surface of epithelial cells leads to a loss of host cell polarity and clustering of NF- $\mathrm{kB}$ signaling components, ultimately resulting in broad transcriptional upregulation of the proinflammatory cytokines IL-6, IL-8, and TNF- $\alpha$ [21]. ExoU activity leads to IL-1 $\alpha$ release from necrotic cells, generating an inflammasome-independent IL-1 signal that contributes to $P$. aeruginosa recognition in the infected mouse lung [22].

\section{Innate Immune Recognition of $\mathrm{P}$. aeruginosa}

Innate immune receptors can respond to several pathogen-associated molecular patterns present on the $P$. aeruginosa cell surface. Lipopolysaccharide (LPS) activates Toll-like receptor (TLR) 4, with the strongest responses of human TLR4 reserved for P. aeruginosa LPS in which the lipid A side chains are hyperacylated, as is often observed in isolates from chronically infected CF patients $[23,24]$. The contribution of caspase- 11 , a recently described receptor for LPS and a component of the noncanonical inflammasome, to $P$. aeruginosa sensing remains to be determined [25-27]. TLR5 is activated by P. aeruginosa flagellin, with receptor-pathogen-associated molecular pattern interactions occurring once bacteria access the basolateral surface of epithelia where the receptor is expressed. Unmethylated bacterial CpG DNA strongly stimulates TLR9 [28] and likely contributes to sensing of $P$. aeruginosa bacteria and extracellular-DNA-containing biofilms, as TLR9 ${ }^{-1-}$ mice can resist lethal challenge with $P$. aeruginosa [29]. P. aeruginosa also releases outer membrane vesicles that activate TLR-dependent responses in epithelial cells via delivered protein and LPS cargo [30]. Outer membrane vesicles intersect the endocytic pathway to deliver peptidoglycan to NOD-1, a member of the Nod-like receptor (NLR) family that interacts with the adaptor RIP-2 to activate NF- $\kappa B$ and mitogen-activated protein kinase signaling in epithelial cells [31]. Even small noncoding sRNA found in outer membrane vesicles may have immunomodulatory properties, as recently described using a cultured airway epithelial cell system [32]. The bacterial nucleoside diphosphate kinase (Ndk) of $P$. aeruginosa switches phosphate groups between nucleoside diphosphate moieties and was previously found to disrupt ATP levels in macrophages, causing cytotoxicity [33]. Together with flagellin, Ndk has also been found to

$P$. aeruginosa Infection and Inflammation induce expression of IL-1 $\alpha$, IL- $1 \beta$, and IL- 8 via Akt phosphorylation and therefore amplification of NF- $\kappa B$ signaling $[34,35]$.

\section{Sensing "Virulence" via Intracellular Surveillance Mechanisms}

The T3SS of $P$. aeruginosa, which injects bacterial effectors into eukaryotic cells (and may provide a route for substrates of the related flagellar secretion system to access the host cell cytosol [36]) mediates $P$. aeruginosa recognition by cytosolic pattern recognition receptors associated with inflammasomes. These multimolecular signaling platforms assemble in macrophages and dendritic cells when bacterial products are bound by pattern recognition receptors, and they result in the cleavage and activation of procaspase-1, which leads to processing and secretion of the proinflammatory cytokines IL- $1 \beta$ and IL18 and/or pyroptotic cell death [reviewed in 37-39]. Of the numerous inflammasomes described thus far, the NLRC4 and NLRP3 inflammasomes appear to contribute most significantly to $P$. aeruginosa pathogenesis. Expression of both pro-IL- $1 \beta$ and NLRP3 is induced upon activation of TLR $2,3,4$, or 7, essentially priming the cell for subsequent inflammasome activation [40]. Assembly of the NLRC4 inflammasome in murine cells is triggered when intracellular NAIP recognize and bind the T3SS needle (NAIP1) or rod (NAIP2) proteins or intracellular flagellin (NAIP5/NAIP6) [41, 42]. Humans appear to express only one full-length NAIP known to bind a T3SS needle protein (Cpr1) from Chromobacterium violaceum, raising the possibility that the human NLRC4 inflammasome specifically detects T3SS needle proteins of Gramnegative pathogens [43]. Although the adaptor protein ASC is required for murine macrophage activation of the NLRC4 inflammasome, neutrophils can generate IL- $1 \beta$ in an ASC-independent but caspase-1-dependent manner [11]. Thus multiple mechanisms - in various cell types - can contribute to the initiation and propagation of an IL-1 $\beta$-dependent inflammatory response during infection.

Inflammasome activation is closely tied to mitochondrial damage and dysfunction. In bone marrow-derived macrophages, mitochondrial damage can be observed following infection with T3SS expressing bacteria and interestingly - appears to lie upstream of NLRC4 activation. Experimental depletion of mitochondria, or autophagy of damaged mitochondria, significantly attenuates inflammasome activation [44]. Mitochondrial dysfunction can also promote assembly of the NLRP3 inflammasome, which is canonically activated by pore-forming 
toxins, ATP, and crystalline substances such as uric acid [37]. Mutation of the CFTR in airway epithelial cells appears to perturb mitochondrial calcium signaling following $P$. aeruginosa infection - specifically in response to TLR 5 activation by flagellin - and promotes hyperactivation of both NLRP3 and NLRC4 pathways in this model system [45].

The relative contribution of these two inflammasomes to $P$. aeruginosa infection remains an active area of investigation, with Iannitti et al. [46] recently suggesting that the activation of NLRP3 versus NLRC4 leads to disparate outcomes in $\mathrm{P}$. aeruginosa-infected mice. $\mathrm{Nlrc4}^{-/-}$mice infected with an uncharacterized clinical $P$. aeruginosa isolate were unable to control bacterial growth and succumbed to pulmonary infection, while $\mathrm{Nlrp3}^{-/-}$mice showed no defect in bacterial clearance. The authors suggest that NLRC4-dependent production of the IL-1R antagonist IL-1Ra may inhibit overexuberant and pathogenic inflammation due to NLRP3. As NLRC4 activation is defective in $\mathrm{Cftr}^{-/-}$mice, the authors support their model by demonstrating that anakinra (recombinant IL$1 \mathrm{Ra}$ ) can protect $C \mathrm{ftr}^{-/-}$animals from $P$. aeruginosa infection. The clinical implications of these findings are still unclear but suggest that disparate data in the literature as to whether inflammasome activation is beneficial or detrimental to a $P$. aeruginosa-infected host may reflect different pathways and degrees of NLRP3 versus NLRC4 activation by phenotypically distinct bacterial strains.

\section{Mixed Messages: Interferon Signals during}

$\mathrm{P}$. aeruginosa Infection

One important consequence of intra- and extracellular pattern recognition receptor activation is the production of CXC and CC chemokines that recruit immune cells to the site of infection and appropriately activate them, as will be discussed below. P. aeruginosa extracellular infection also prompts an interferon (IFN) response that likely plays significant roles in both proinflammatory and anti-inflammatory pathways. LPS interactions with TLR4 activate both MyD88- and TRIF-dependent pathways, with the latter leading to a type I IFN response marked by the production of IFN- $\beta$ [47]. Type I IFN signaling via the transcription factor STAT1 can repress NLRP3 inflammasome production of the proinflammatory cytokine IL$1 \beta$ [48]. Pretreatment of primary murine AM with type I IFN or stimulation of type I IFN signaling in WT mice resulted in significantly decreased IL- $1 \beta$ and IL- 18 production in the context of $P$. aeruginosa infection, with improvement in bacterial clearance and reduced tissue damage in the murine acute pneumonia model [49]. In contrast, the type III IFN response of epithelial cells, which appears to be elicited by the same TLR ligands as a type I IFN response [50], leads to IFN- $\lambda$ production, which may enhance inflammation to the detriment of the host. IFN- $\lambda$ signaling through the IFN- $\lambda$ receptor (composed of IL$28 \mathrm{R} \alpha$ and IL-10R $\beta$ ) and IFN- $\beta$ signaling through the IFNa/ $\beta$ receptor have been shown to stimulate $P$. aeruginosa biofilm growth on airway epithelial cells [51]. IFN- $\lambda$ signals via STAT3 to inhibit microRNA miR-21 production, resulting in sustained expression of PDCD4, a positive regulator of proinflammatory pathways during infection. Disruption of the IFN- $\lambda$ receptor in IL-28R knockout mice has been associated with improved survival and bacterial clearance, as well as increased production of the anti-inflammatory cytokine IL-10 [52]. These epithelial IFN responses are also elicited by viruses [53] and may contribute to the increased susceptibility of the respiratory tract to infection by $P$. aeruginosa and other bacterial opportunists after viral infection $[51,54]$.

It seems clear that inflammation is necessary for bacterial clearance, and yet exuberant inflammatory responses are associated with impaired bacterial clearance and increased host morbidity. Elevated levels of proinflammatory cytokines are correlated with immune-mediated destruction of lung parenchyma in diseases such as COPD [55]. Fibrosis is a frequent consequence of the body's attempt to resolve the vicious cycle of inflammation and airway epithelial injury, and it often results in the replacement of gas-exchanging lung with scar tissue. This can lead to life-threatening complications of infection such as bronchiolitis obliterans syndrome (BOS), in which inflammatory responses cause obstruction of narrow airways. Fibroblast activation can be driven by products of $P$. aeruginosa-injured epithelial cells such as IL-1a and may underlie the development of BOS in lung transplant patients infected with $P$. aeruginosa. These individuals show increased levels of IL- $1 \alpha$, elevated IL- 8 levels, and higher neutrophil percentages in bronchoalveolar lavage fluid collected shortly before the diagnosis of BOS, as compared to posttransplant patients without BOS, and inflammation is temporally correlated with $P$. aeruginosa growth in bronchoalveolar lavage [56].

IL-17 signaling may also promote ongoing inflammation and tissue damage during $P$. aeruginosa infection. Although the beneficial versus detrimental role of IL-17

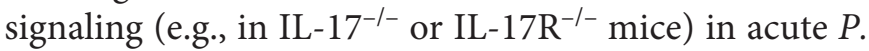
aeruginosa infection is still debated $[57,58]$, the absence of IL-17 signaling has been linked to an increased incidence of chronic $P$. aeruginosa infection, an increased bacterial burden, and decreased survival in recent studies 
$[59,60]$. Lore et al. [59] noted, however, that chronically infected IL-17a $\mathrm{a}^{-1-}$ mice showed less pulmonary inflammation and tissue damage than wild-type counterparts, consistent with IL-17-mediated increases in matrix metalloproteinase secretion and tissue remodeling [61]. By administering anti-IL-17a mAb to chronically infected wild-type mice, they were able to inhibit neutrophil infiltration and decrease levels of biomarkers associated with tissue remodeling and damage (pro-MMP-9 and TGF- $\beta$ ) [59]. These examples illustrate the complexity of inflammatory signaling during $P$. aeruginosa infection, with cytokines having different effects depending on the target cell or phase of infection being examined.

\section{Inflammation: Balancing Bacterial Clearance with Collateral Damage to the Host}

The complement system is required for murine survival following $P$. aeruginosa lung infection $[62,63]$. The antimicrobial activity of these serum proteins is enhanced in the acidic and hypocalcemic conditions characteristic of infected and inflamed tissue [64]. The $P$. aeruginosa outer membrane porin OprF serves as a binding acceptor molecule for $\mathrm{C} 3 \mathrm{~b}$ to initiate formation of the membrane attack complex (MAC) [65], but another bacterial protein, dihydrolipoamide dehydrogenase (Lpd), can inhibit MAC deposition and limit complement damage [66]. Of interest, $P$. aeruginosa can stimulate neutrophils to undergo neutrophil extracellular trap (NET) formation with activation and deposition of the C5b-9 MAC on NET, potentially contributing to local host cell damage and death [67].

The primary cellular responders during acute $P$. aeruginosa infection are tissue-resident $\mathrm{AM}$ and recruited neutrophils and natural killer cells. AM surveil the lung, contributing to both pathogen recognition/immune signaling and antigen presentation. Natural killer cells, together with AM and dendritic cells, may be required for maximal IFN- $\gamma$ production [68]. Inflammasome activation and subsequent generation of IL-1 $\beta$ are sensed by IL-1R-expressing airway epithelial cells, which respond by producing chemokines, such as IL- 8 , that rapidly recruit neutrophils to the airways [69] and upregulate their antimicrobial ROS activity via the CXCR2 and CXCR1 receptors, respectively [70]. A functional CXCR1 "deficiency" appears to occur in patients with CF and other chronic lung diseases, such as COPD and bronchiectasis, due to excess serine protease activity in the inflamed airways. This deficiency may contribute significantly to impaired bacterial killing in this setting, as treatment of CF patients with inhaled $\alpha_{1}$-antitrypsin reduces the $P$. aeruginosa burden in sputum [71].

$P$. aeruginosa Infection and Inflammation
Although neutrophil recruitment is required for $P$. aeruginosa phagocytosis and clearance [reviewed in 3], this bacterium can evade neutrophilic killing through numerous mechanisms. Bacterial absorption of host-derived sialoglycoproteins (Sias) allows $P$. aeruginosa to inhibit neutrophil effector functions, including degranulation, ROS production, and NET formation, via Sias-siglec-9 interactions [72]. The T3SS effector ExoU rapidly kills recruited neutrophils, essentially resulting in localized immunosuppression [73], while ExoS and ExoT inhibit actin-dependent migration and phagocytosis and lead to neutrophil apoptosis [74]. Even fully functional neutrophils, however, are frustrated in their ability to phagocytize and kill $P$. aeruginosa within biofilms [75]. This incapacity may have further consequences; experimentally impairing neutrophilic elimination of $P$. aeruginosa via knockout of the Nox2 NADPH oxidase resulted in flagellin-mediated neutrophil pyroptosis that was dependent on NLRC4 and TLR5 activity [76].

While a neutrophilic inflammatory response is necessary for $P$. aeruginosa clearance, a hyperinflammatory and nonresolving response associated with poor host outcomes is often observed in vivo. Outcomes in a murine model of acute $P$. aeruginosa pneumonia improved after inhibition of flagellin-dependent NLRC4 inflammasome signaling in AM, likely due to a decrease in IL- $1 \beta$ production [49]. The resistance of $P$. aeruginosa to killing undoubtedly contributes to ongoing inflammation and neutrophil recruitment, while activation of particular host pathways, as detailed above, may lead to overexuberant but ineffective innate effector mechanisms. Bacterially secreted degradative enzymes and toxins combine with host-derived inflammatory mediators to disrupt tight junctions in mucosal and alveolar epithelia, leading to edema, a reduced gas exchange, and impaired lung function [77].

Resolution of an acute inflammatory response requires dampening of proinflammatory pathways and catabolism of proinflammatory mediators. Apoptotic neutrophils are cleared by newly arrived macrophages and monocytes, which also promote the generation of regulatory T cells (Tregs) [reviewed in 78]. These Tregs inhibit proinflammatory cytokine secretion, kill cytotoxic cells, and secrete anti-inflammatory cytokines. Meanwhile, antigen-presenting dendritic cells traffic to local lymph nodes and initiate adaptive immune responses to pathogens [79]. Recent work suggests that this process is also disrupted when $P$. aeruginosa cannot be cleared from the airways, and persistent neutrophilic inflammation is accompanied by increased effector T-cell responses (marked 
by elevated IFN- $\gamma$, IL-6, IL-1 $\beta$, and IL-17) and decreased IL-10 and Tregs [80]. It is in such an environment that $P$. aeruginosa establishes chronic colonization.

\section{Survival of the Fittest: Adapted to Thrive in the Inflamed Lung}

A pathognomonic feature of $P$. aeruginosa is its ability to transition from acute infection to chronic colonization in certain hosts, including patients with CF or COPD or individuals who are chronically intubated. Bacterial and host factors that lead to failed clearance of the infected airway are likely important for this transition, though this is difficult to test directly in murine pneumonia models, where the acute-to-chronic transition is not observed. In the following section we review what has been learned about this transition from infecting mice with agar-encapsulated $P$. aeruginosa, from characterizing new nonmurine models of CF (such as the pig and ferret [81]), and from increasingly sophisticated analyses of patients chronically infected with this organism.

\section{P. aeruginosa Behaviors that Confer Fitness in the}

Setting of Inflammation

Inflammation is a feature of the CF airway observed in many children long before a bacterial or fungal pathogen can be isolated from their airways [82]. Many factors likely contribute to this hyperinflammatory environment. The desiccated, thick mucus that results from a reduced or absent CFTR function impairs mechanical clearance of any aspirated bacteria, leading to a bacterial presence in normally sterile lungs [83]. This proinflammatory stimulus is coupled with exaggerated and dysregulated responses of $\mathrm{Cftr}^{-1-}$ epithelial and immune cells to microbial ligands and to host-derived inflammatory mediators [reviewed in 84], creating an inflamed environment to which $P$. aeruginosa is relatively well adapted. Such adaptations, described below, also appear to favor fitness of enteric pathogens in the inflamed intestine [reviewed in 85].

In states of chronic inflammation, the host sequesters free iron, a critical nutrient for bacterial metabolism. $P$. aeruginosa expresses numerous siderophores for scavenging adequate iron, which is required for nucleic acid biosynthesis and electron transport, among other critical biochemical pathways. During chronic infection, $P$. aeruginosa undergoes a positive selection for mutants with an increased ability to scavenge iron, including increased transcription of the FpvA pyoverdine siderophore pro- tein and $p h u$ heme utilization system [86]. Sputum samples of CF patients have relatively high iron levels compared to those of healthy controls [87], and therefore their lungs may provide a more permissive environment for biofilm formation; high iron levels have been found to inhibit repressors of Psl synthesis, a polysaccharide component of biofilms. Psl in turn binds iron for storage and may sequester it for biofilm community use [88]. Changes in iron availability may also underlie the increased susceptibility to $P$. aeruginosa after viral infection; respiratory syncytial virus increases the iron availability in murine airway epithelial cells due to the apical release of transferrin, promoting the transition of $P$. aeruginosa to growth in biofilms [51].

$P$. aeruginosa likely experiences hypoxia and near anoxia during pulmonary infection. The bacterial biofilms characteristic of chronically infected airways significantly limit the transfer rate of oxygen from gas to liquid phase, which minimizes the bacterial exposure to host oxidative stress but also places them in micro- or anaerobic conditions [89]. Recruited neutrophils consume and further deplete the available oxygen [90], to which the "obligate aerobe" $P$. aeruginosa responds by upregulating pathways that allow it to respire using nitrate as a terminal electron acceptor, i.e., by denitrification [91-93]. This strategy may share features with that employed by pathogenic Enterobacteriaceae, which can use by-products of the host inflammatory response as terminal electron acceptors to outcompete obligate aerobes in the inflamed gut [85].

$P$. aeruginosa can survive in the relatively anoxic, ironlimited environment of the chronically infected airway, but its growth rate appears to be decreased in this setting [90]. Since a majority of antibiotic classes target pathways upregulated primarily in actively dividing bacteria, some authors speculate that decreased or absent bacterial growth may contribute to increased antimicrobial resistance. The high levels of antibiotic resistance of biofilmgrown bacteria, which appear to dominate in chronically infected airways, are well documented. Additionally, the chronically infected CF airway selects for P. aeruginosa mutants with lipid A species modified via hyperacylation or the addition of aminoarabinose, which confer increased resistance to host antimicrobial peptides [94, 95]. Interestingly, the hexa- and hepta-acylated forms of lipid A are much stronger activators of human TLR4 than the penta-acylated form characteristic of non-CF patient isolates, again supporting the notion that $P$. aeruginosa has a survival advantage in the inflamed lung, and selection occurs for adaptations that promote this type of environment. In a similar vein, lasR quorum-sensing mu- 
tants - which frequently arise in chronically infected CF patients - are also associated with greater neutrophilic inflammation and immunopathology in both murine models and human patients colonized with these variants [96].

Recent genomic studies have provided an increasingly sophisticated view of $P$. aeruginosa adaptation in the chronically infected airway [reviewed in 97]. The dissection of explanted CF lungs from patients undergoing lung transplantation, and the subsequent phenotypic, proteomic, and whole-genome sequencing studies of isolates collected from spatially distinct regions of the same lung, revealed numerous subpopulations that were mostly derived from a single lineage but that had undergone independent evolution with very limited intermixing. These regional isolates showed a marked heterogeneity of genotype and phenotype with regard to nutritional requirements, stress resistance, antimicrobial resistance, and virulence [98]. As a consequence, a given individual was infected by a diverse array of bacterial variants with a high adaptability to changing conditions within the host. Although previous sequencing studies have demonstrated selection for many of these genetic mutations in chronic CF isolates [99], this paper makes the somewhat unexpected point that $P$. aeruginosa heterogeneity within a chronically infected individual may underlie this pathogen's uncanny persistence.

\section{Modulating Inflammation: a Viable Strategy for Treating Multi-Drug-Resistant $P$. aeruginosa?}

The intrinsic and acquired antibiotic resistance exhibited by $P$. aeruginosa isolates, particularly those from chronically infected individuals, has left many patients with few options for antibiotic therapy. As $P$. aeruginosa pathogenesis appears to be driven in no small part by immune-mediated pulmonary damage, it is worth considering whether approaches that might temper or modulate inflammation could be used to treat $P$. aeruginosa infections. Indeed, the benefit of azithromycin has been attributed to its anti-inflammatory effects, namely the reduction of cellular infiltration and inhibition of cytokine release (TNF- $\alpha$ and macrophage inflammatory protein-2), as observed in a CF mouse model [100].

First, some cautionary data drive home the point that the immune response does contribute to bacterial clearance. A clinical trial of the leukotriene $\mathrm{B} 4\left(\mathrm{LTB}_{4}\right)$-receptor antagonist BIIL $284 \mathrm{BS}$ in CF patients was prematurely terminated after an interim analysis revealed a significant increase in pulmonary related serious adverse events in adults treated with the compound as compared to placebo-treated controls [101]. In follow-up studies, the compound was administered to mice prior to infection with agar bead-embedded $P$. aeruginosa. Inhibition of $\mathrm{LTB}_{4}$ signaling inhibited neutrophil recruitment to the lungs, resulted in increased bacterial loads in the lung, and was associated with bacteremia/sepsis [102].

Other immune modulators have shown some benefit in $P$. aeruginosa infection models, as alluded to earlier. Anakinra (rIL-1Ra) treatment appears to benefit $P$. aeruginosa-infected $\mathrm{Cftr}^{-/-}$mice, presumably by compensating for the lack of NLRC4-dependent IL-1Ra and thereby suppressing inappropriate activation of the NLRP3 inflammasome [46]. Recombinant human interleukin-7 (rhIL-7) improved survival in mouse models of sepsis by increasing the number of immune effector cells and innate lymphoid cells in the lung, as well as the production of IL-17, IFN- $\gamma$, and TNF- $\alpha$ [103]. Inhaled $\alpha_{1}$-antitrypsin appeared to benefit individuals with $\mathrm{CF}$ and high free elastase levels in bronchoalveolar lavage fluid, leading to increased CXCR1 surface expression on neutrophils and improved $P$. aeruginosa killing [71]. Other immunomodulators - miglustat and Genz-529648, both $\beta$-glucosidase 2 inhibitors that alter the sphingolipid metabolism show anti-inflammatory effects in epithelial cell models of $P$. aeruginosa infection but have not been tested more extensively [104, 105]. Antibody therapies are also being actively pursued, although whether pro- or anti-inflammatory properties are desired has yet to be determined. The use of the TLR4 agonist antibody UT12 promoted bacterial clearance, neutrophilic recruitment, and macrophage inflammatory protein 2 (MIP-2) production in the lungs [106]. Conversely, blockade of IL-17A with a monoclonal antibody resulted in decreased neutrophilic infiltration and possible increased host tolerance of infection, as evidence by lower levels of the tissue damage markers pro-MMP-9 and TGF- $\beta_{1}$ [59].

Bone-marrow-derived mesenchymal stem cells may have beneficial immunomodulatory activity in the setting of acute pneumonia. Administration of these cells can inhibit cytotoxic NK and effector T cells, promote Treg differentiation, and suppress proinflammatory cytokine production. Isolated multipotent murine mesenchymal stem cells were used to treat a mouse model of pulmonary infection with Klebsiella pneumoniae, resulting in a reduction of proinflammatory cytokines, dendritic cells, and CD4+ T cells in addition to improved survival with no increase in the bacterial load [107]. This therapy may be applicable to other Gram-negative lung pathogens, such as $P$. aeruginosa. 


\section{Future Directions}

Multi-drug-resistant strains of $P$. aeruginosa will continue to present a persistent and critical danger to CF and immunocompromised patients, particularly in intensive care settings. The clinical goal of preventing death due to septic shock or inhibition of alveolar gas exchange in the context of $P$. aeruginosa-induced pneumonia will necessitate addressing the hyperinflammatory response. Success in this endeavor will require continued research of the interaction between $P$. aeruginosa and host tissues in pulmonary infection models and the development of immunomodulatory therapies.

\section{References}

1 Lavoie EG, Wangdi T, Kazmierczak BI: Innate immune responses to Pseudomonas aeruginosa infection. Microbes Infect 2011;13: 1133-1145.

2 Parker D, Ahn D, Cohen T, Prince A: Innate immune signaling activated by MDR bacteria in the airway. Physiol Rev 2016;96:19-53.

3 Lovewell RR, Patankar YR, Berwin B: Mechanisms of phagocytosis and host clearance of Pseudomonas aeruginosa. Am J Physiol Lung Cell Mol Physiol 2014;306:L591-L603.

4 Preu L, Bischoff M, Veith NT, Rosenbruch M, Theegarten D, Laschke MW, Meier C, Tschernig T: Initial host response to bacteria in the murine lung differs between Pseudomonas aeruginosa, Staphylococcus aureus and Streptococcus pneumoniae. Inflammation 2015;39:1-5.

5 Goncalves-de-Albuquerque CF, Silva AR, Burth P, Rocco PR, Castro-Faria MV, CastroFaria-Neto HC: Possible mechanisms of Pseudomonas aeruginosa-associated lung disease. Int J Med Microbiol 2016;306:20-28.

6 Kukavica-Ibrulj I, Facchini M, Cigana C, Levesque RC, Bragonzi A: Assessing Pseudomonas aeruginosa virulence and the host response using murine models of acute and chronic lung infection. Methods Mol Biol 2014;1149:757-771.

7 Kung VL, Ozer EA, Hauser AR: The accessory genome of Pseudomonas aeruginosa. Microbiol Mol Biol Rev 2010;74:621-641.

8 Mosquera-Rendon J, Rada-Bravo AM, Cardenas-Brito S, Corredor M, Restrepo-Pineda E, Benitez-Paez A: Pangenome-wide and molecular evolution analyses of the Pseudomonas aeruginosa species. BMC Genomics 2016;17: 45.

9 Schultz MJ, Rijneveld AW, Florquin S, Edwards CK, Dinarello CA, van der Poll T: Role of interleukin-1 in the pulmonary immune response during Pseudomonas aeruginosa pneumonia. Am J Physiol Lung Cell Mol Physiol 2002;282:L285-L290.

10 Spagnuolo L, De Simone M, Lore NI, De Fino I, Basso V, Mondino A, Cigana C, Bragonzi A: The host genetic background defines diverse immune-reactivity and susceptibility to chronic Pseudomonas aeruginosa respiratory infection. Sci Rep 2016;6:36924.
11 Patankar YR, Mabaera R, Berwin B: Differential ASC requirements reveal a key role for neutrophils and a noncanonical IL-1beta response to Pseudomonas aeruginosa. Am J Physiol Lung Cell Mol Physiol 2015;309: L902-L913.

12 Mansour SC, Pena OM, Hancock RE: Host defense peptides: front-line immunomodulators. Trends Immunol 2014;35:443-450.

$13 \mathrm{Wu} \mathrm{H}$, Kuzmenko A, Wan S, Schaffer L, Weiss A, Fisher JH, Kim KS, McCormack FX: Surfactant proteins A and D inhibit the growth of Gram-negative bacteria by increasing membrane permeability. J Clin Invest 2003;111:1589-1602.

14 Heiniger RW, Winther-Larsen HC, Pickles RJ, Koomey M, Wolfgang MC: Infection of human mucosal tissue by Pseudomonas aeruginosa requires sequential and mutually dependent virulence factors and a novel pilusassociated adhesin. Cell Microbiol 2010;12: 1158-1173.

15 Golovkine G, Faudry E, Bouillot S, Elsen S, Attree I, Huber P: Pseudomonas aeruginosa transmigrates at epithelial cell-cell junctions, exploiting sites of cell division and senescent cell extrusion. PLoS Pathog 2016;12:e1005377.

16 Wood S, Goldufsky J, Shafikhani SH: Pseudomonas aeruginosa ExoT induces atypical anoikis apoptosis in target host cells by transforming Crk adaptor protein into a cytotoxin. PLoS Pathog 2015;11:e1004934.

17 Wood SJ, Goldufsky JW, Bello D, Masood S, Shafikhani SH: Pseudomonas aeruginosa ExoT induces mitochondrial apoptosis in target host cells in a manner that depends on its GTPase-activating protein (GAP) domain activity. J Biol Chem 2015;290:29063-29073.

18 Shafikhani SH, Engel J: Pseudomonas aeruginosa type III-secreted toxin ExoT inhibits host-cell division by targeting cytokinesis at multiple steps. Proc Natl Acad Sci USA 2006; 103:15605-15610.

19 Rangel SM, Diaz MH, Knoten CA, Zhang A, Hauser AR: The role of ExoS in dissemination of Pseudomonas aeruginosa during pneumonia. PLoS Pathog 2015;11:e1004945.
20 Stevens TC, Ochoa CD, Morrow KA, Robson MJ, Prasain N, Zhou C, Alvarez DF, Frank DW, Balczon R, Stevens T: The Pseudomonas aeruginosa exoenzyme $\mathrm{Y}$ impairs endothelial cell proliferation and vascular repair following lung injury. Am J Physiol Lung Cell Mol Physiol 2014;306:L915-L924.

21 Tran CS, Eran Y, Ruch TR, Bryant DM, Datta A, Brakeman P, Kierbel A, Wittmann T, Metzger RJ, Mostov KE, Engel JN: Host cell polarity proteins participate in innate immunity to Pseudomonas aeruginosa infection. Cell Host Microbe 2014;15:636-643.

22 Stephenson HN, Herzig A, Zychlinsky A: Beyond the grave: when is cell death critical for immunity to infection? Curr Opin Immunol 2016;38:59-66.

23 Hajjar AM, Ernst RK, Tsai JH, Wilson CB, Miller SI: Human Toll-like receptor 4 recognizes host-specific LPS modifications. Nat Immunol 2002;3:354-359.

24 Ernst RK, Yi EC, Guo L, Lim KB, Burns JL, Hackett M, Miller SI: Specific lipopolysaccharide found in cystic fibrosis airway Pseudomonas aeruginosa. Science 1999;286:1561-1565.

25 Kayagaki N, Wong MT, Stowe IB, Ramani SR, Gonzalez LC, Akashi-Takamura S, Miyake K, Zhang J, Lee WP, Muszynski A, Forsberg LS, Carlson RW, Dixit VM: Noncanonical inflammasome activation by intracellular LPS independent of TLR4. Science 2013;341: 1246-1249.

26 Shi J, Zhao Y, Wang Y, Gao W, Ding J, Li P, $\mathrm{Hu}$ L, Shao F: Inflammatory caspases are innate immune receptors for intracellular LPS Nature 2014;514:187-192.

27 Hagar JA, Powell DA, Aachoui Y, Ernst RK, Miao EA: Cytoplasmic LPS activates caspase-11: implications in TLR4-independent endotoxic shock. Science 2013;341:1250-1253.

28 Magnusson M, Tobes R, Sancho J, Pareja E: Cutting edge: natural DNA repetitive extragenic sequences from gram-negative pathogens strongly stimulate TLR9. J Immunol 2007;179:31-35.

29 Benmohamed F, Medina M, Wu YZ, Maschalidi S, Jouvion G, Guillemot L, Chignard M, Manoury B, Touqui L: Toll-like receptor 9 deficiency protects mice against Pseudomonas aeruginosa lung infection. PLoS One 2014;9:e90466. 
30 Ellis TN, Leiman SA, Kuehn MJ: Naturally produced outer membrane vesicles from Pseudomonas aeruginosa elicit a potent innate immune response via combined sensing of both lipopolysaccharide and protein components. Infect Immun 2010;78:3822-3831.

31 Irving AT, Mimuro H, Kufer TA, Lo C, Wheeler R, Turner LJ, Thomas BJ, Malosse C, Gantier MP, Casillas LN, Votta BJ, Bertin J, Boneca IG, Sasakawa C, Philpott DJ, Ferrero RL, Kaparakis-Liaskos M: The immune receptor NOD1 and kinase RIP2 interact with bacterial peptidoglycan on early endosomes to promote autophagy and inflammatory signaling. Cell Host Microbe 2014;15:623-635.

32 Koeppen K, Hampton TH, Jarek M, Scharfe M, Gerber SA, Mielcarz DW, Demers EG, Dolben EL, Hammond JH, Hogan DA, Stanton BA: A novel mechanism of host-pathogen interaction through sRNA in bacterial outer membrane vesicles. PLoS Pathog 2016; 12:e1005672.

33 Zaborina O, Misra N, Kostal J, Kamath S, Kapatral V, El-Idrissi ME, Prabhakar BS, Chakrabarty AM: P2Z-Independent and P2Z receptor-mediated macrophage killing by Pseudomonas aeruginosa isolated from cystic fibrosis patients. Infect Immun 1999;67: 5231-5242.

34 Kim YJ, Paek SH, Jin S, Park BS, Ha UH: A novel Pseudomonas aeruginosa-derived effector cooperates with flagella to mediate the upregulation of interleukin 8 in human epithelial cells. Microb Pathog 2014;66:24-28.

35 Kim YJ, Lee JH, Lee Y, Jia J, Paek SH, Kim HB, Jin S, Ha UH: Nucleoside diphosphate kinase and flagellin from Pseudomonas aeruginosa induce interleukin 1 expression via the Akt/ NF-kappaB signaling pathways. Infect Immun 2014;82:3252-3260.

36 Ince D, Sutterwala FS, Yahr TL: Secretion of flagellar proteins by the Pseudomonas aeruginosa type III secretion-injectisome system. J Bacteriol 2015;197:2003-2011.

37 Vanaja SK, Rathinam VA, Fitzgerald KA: Mechanisms of inflammasome activation: recent advances and novel insights. Trends Cell Biol 2015;25:308-315.

38 Vance RE: The NAIP/NLRC4 inflammasomes. Curr Opin Immunol 2015;32:84-89.

39 Wonnenberg B, Bischoff M, Beisswenger C, Dinh T, Bals R, Singh B, Tschernig T: The role of IL-1beta in Pseudomonas aeruginosa in lung infection. Cell Tissue Res 2016;364:225-229.

40 Bauernfeind FG, Horvath G, Stutz A, Alnemri ES, MacDonald K, Speert D, FernandesAlnemri T, Wu J, Monks BG, Fitzgerald KA, Hornung V, Latz E: Cutting edge: NF-kappaB activating pattern recognition and cytokine receptors license NLRP3 inflammasome activation by regulating NLRP 3 expression. J Immunol 2009;183:787-791.

41 Tenthorey JL, Kofoed EM, Daugherty MD, Malik HS, Vance RE: Molecular basis for specific recognition of bacterial ligands by NAIP/ NLRC4 inflammasomes. Mol Cell 2014;54: $17-29$.
42 Rauch I, Tenthorey JL, Nichols RD, Al Moussawi K, Kang JJ, Kang C, Kazmierczak BI, Vance RE: NAIP proteins are required for $\mathrm{cy}$ tosolic detection of specific bacterial ligands in vivo. J Exp Med 2016;213:657-665.

43 Zhao Y, Yang J, Shi J, Gong YN, Lu Q, Xu H, Liu L, Shao F: The NLRC4 inflammasome receptors for bacterial flagellin and type III secretion apparatus. Nature 2011;477:596-600.

44 Jabir MS, Hopkins L, Ritchie ND, Ullah I, Bayes HK, Li D, Tourlomousis P, Lupton A, Puleston D, Simon AK, Bryant C, Evans TJ: Mitochondrial damage contributes to Pseudomonas aeruginosa activation of the inflammasome and is downregulated by autophagy. Autophagy 2015;11:166-182.

45 Rimessi A, Bezzerri V, Patergnani S, Marchi S, Cabrini G, Pinton P: Mitochondrial $\mathrm{Ca}^{2+}$ dependent NLRP3 activation exacerbates the Pseudomonas aeruginosa-driven inflammatory response in cystic fibrosis. Nat Commun 2015;6:6201.

46 Iannitti RG, Napolioni V, Oikonomou V, De Luca A, Galosi C, Pariano M, Massi-Benedetti C, Borghi M, Puccetti M, Lucidi V, Colombo C, Fiscarelli E, Lass-Florl C, Majo F, Cariani L, Russo M, Porcaro L, Ricciotti G, Ellemunter H, Ratclif L, De Benedictis FM, Talesa VN, Dinarello CA, van de Veerdonk FL, Romani L: IL-1 receptor antagonist ameliorates inflammasome-dependent inflammation in murine and human cystic fibrosis. Nat Commun 2016;7:10791.

47 Parker D, Cohen TS, Alhede M, Harfenist BS, Martin FJ, Prince A: Induction of type I interferon signaling by Pseudomonas aeruginosa is diminished in cystic fibrosis epithelial cells. Am J Respir Cell Mol Biol 2012;46:6-13.

48 Guarda G, Braun M, Staehli F, Tardivel A, Mattmann C, Forster I, Farlik M, Decker T, Du Pasquier RA, Romero P, Tschopp J: Type I interferon inhibits interleukin-1 production and inflammasome activation. Immunity 2011;34:213-223.

49 Cohen TS, Prince AS: Activation of inflammasome signaling mediates pathology of acute $P$. aeruginosa pneumonia. J Clin Invest 2013;123:1630-1637.

50 Uze G, Monneron D: IL-28 and IL-29: newcomers to the interferon family. Biochimie 2007;89:729-734.

51 Hendricks MR, Lashua LP, Fischer DK, Flitter BA, Eichinger KM, Durbin JE, Sarkar SN, Coyne CB, Empey KM, Bomberger JM: Respiratory syncytial virus infection enhances Pseudomonas aeruginosa biofilm growth through dysregulation of nutritional immunity. Proc Natl Acad Sci USA 2016;113:16421647.

52 Cohen TS, Prince AS: Bacterial pathogens activate a common inflammatory pathway through IFNlambda regulation of PDCD4. PLoS Pathog 2013;9:e1003682.

53 Sadler AJ, Williams BR: Interferon-inducible antiviral effectors. Nat Rev Immunol 2008;8: $559-568$
54 Lee B, Robinson KM, McHugh KJ, Scheller EV, Mandalapu S, Chen C, Di YP, Clay ME, Enelow RI, Dubin PJ, Alcorn JF: Influenzainduced type I interferon enhances susceptibility to gram-negative and gram-positive bacterial pneumonia in mice. Am J Physiol Lung Cell Mol Physiol 2015;309:L158-L167.

55 Barnes PJ: Role of HDAC2 in the pathophysiology of COPD. Annu Rev Physiol 2009;71: 451-464.

56 Borthwick LA, Suwara MI, Carnell SC, Green NJ, Mahida R, Dixon D, Gillespie CS, Cartwright TN, Horabin J, Walker A, Olin E, Rangar M, Gardner A, Mann J, Corris PA, Mann DA, Fisher AJ: Pseudomonas aeruginosa induced airway epithelial injury drives fibroblast activation: a mechanism in chronic lung allograft dysfunction. Am J Transplant 2016; 16:1751-1765.

57 Wonnenberg B, Jungnickel C, Honecker A, Wolf L, Voss M, Bischoff M, Tschernig T, Herr C, Bals R, Beisswenger C: IL-17A attracts inflammatory cells in murine lung infection with $P$. aeruginosa. Innate Immun 2016;22: 620-625.

58 Liu J, Feng Y, Yang K, Li Q, Ye L, Han L, Wan $\mathrm{H}$ : Early production of IL-17 protects against acute pulmonary Pseudomonas aeruginosa infection in mice. FEMS Immunol Med Microbiol 2011;61:179-188.

59 Lore NI, Cigana C, Riva C, De Fino I, Nonis A, Spagnuolo L, Sipione B, Cariani L, Girelli D, Rossi G, Basso V, Colombo C, Mondino A, Bragonzi A: IL-17A impairs host tolerance during airway chronic infection by Pseudomonas aeruginosa. Sci Rep 2016;6:25937.

60 Bayes HK, Ritchie ND, Evans TJ: IL-17 is required for control of chronic lung infection caused by Pseudomonas aeruginosa. Infect Immun 2016;84:3507-3516.

61 Fogli LK, Sundrud MS, Goel S, Bajwa S, Jensen K, Derudder E, Sun A, Coffre M, Uyttenhove C, Van Snick J, Schmidt-Supprian M, Rao A, Grunig G, Durbin J, Casola S, Rajewsky K, Koralov SB: T cell-derived IL-17 mediates epithelial changes in the airway and drives pulmonary neutrophilia. J Immunol 2013;191:3100-3111.

62 Mueller-Ortiz SL, Drouin SM, Wetsel RA The alternative activation pathway and complement component $\mathrm{C} 3$ are critical for a protective immune response against Pseudomonas aeruginosa in a murine model of pneumonia. Infect Immun 2004;72:2899-2906.

63 Younger JG, Shankar-Sinha S, Mickiewicz M, Brinkman AS, Valencia GA, Sarma JV, Younkin EM, Standiford TJ, Zetoune FS, Ward PA: Murine complement interactions with Pseudomonas aeruginosa and their consequences during pneumonia. Am J Respir Cell Mol Biol 2003;29:432-438.

64 Zhang J, Koh J, Lu J, Thiel S, Leong BS, Sethi S, He CY, Ho B, Ding JL: Local inflammation induces complement crosstalk which amplifies the antimicrobial response. PLoS Pathog 2009;5:e1000282 
65 Mishra M, Ressler A, Schlesinger LS, Wozniak DJ: Identification of OprF as a complement component $\mathrm{C} 3$ binding acceptor molecule on the surface of Pseudomonas aeruginosa. Infect Immun 2015;83:3006-3014.

66 Hallstrom T, Uhde M, Singh B, Skerka C, Riesbeck K, Zipfel PF: Pseudomonas aeruginosa uses dihydrolipoamide dehydrogenase (Lpd) to bind to the human terminal pathway regulators vitronectin and clusterin to inhibit terminal pathway complement attack. PLoS One 2015;10:e 0137630

67 Yuen J, Pluthero FG, Douda DN, Riedl M, Cherry A, Ulanova M, Kahr WH, Palaniyar N, Licht C: NETosing neutrophils activate complement both on their own NETs and bacteria via alternative and non-alternative pathways. Front Immunol 2016;7:137.

68 Pastille E, Pohlmann S, Wirsdorfer F, Reib A, Flohe SB: A disturbed interaction with accessory cells upon opportunistic infection with Pseudomonas aeruginosa contributes to an impaired IFN-gamma production of NK cells in the lung during sepsis-induced immunosuppression. Innate Immun 2015;21:115126.

69 Mijares LA, Wangdi T, Sokol C, Homer R, Medzhitov R, Kazmierczak BI: Airway epithelial MyD88 restores control of Pseudomonas aeruginosa murine infection via an IL-1-dependent pathway. J Immunol 2011;186:70807088 .

70 Carevic M, Oz H, Fuchs K, Laval J, Schroth C, Frey N, Hector A, Bilich T, Haug M, Schmidt A, Autenrieth SE, Bucher K, Beer-Hammer S, Gaggar A, Kneilling M, Benarafa C, Gao JL, Murphy PM, Schwarz S, Moepps B, Hartl D: CXCR1 regulates pulmonary anti-Pseudomonas host defense. J Innate Immun 2016;8: 362-373.

71 Hartl D, Latzin P, Hordijk P, Marcos V, Rudolph C, Woischnik M, Krauss-Etschmann S, Koller B, Reinhardt D, Roscher AA, Roos D, Griese M: Cleavage of CXCR1 on neutrophils disables bacterial killing in cystic fibrosis lung disease. Nat Med 2007;13:1423-1430.

72 Khatua B, Bhattacharya K, Mandal C: Sialoglycoproteins adsorbed by Pseudomonas aeruginosa facilitate their survival by impeding neutrophil extracellular trap through siglec-9. J Leukoc Biol 2012;91:641-655.

73 Diaz MH, Shaver CM, King JD, Musunuri S, Kazzaz JA, Hauser AR: Pseudomonas aeruginosa induces localized immunosuppression during pneumonia. Infect Immun 2008;76: 4414-4421.

74 Sun Y, Karmakar M, Taylor PR, Rietsch A, Pearlman E: ExoS and ExoT ADP ribosyltransferase activities mediate Pseudomonas aeruginosa keratitis by promoting neutrophil apoptosis and bacterial survival. J Immunol 2012;188:1884-1895

75 Alhede M, Bjarnsholt T, Givskov M, Alhede M: Pseudomonas aeruginosa biofilms: mechanisms of immune evasion. Adv Appl Microbiol 2014;86:1-40.
76 Ryu JC, Kim MJ, Kwon Y, Oh JH, Yoon SS, Shin SJ, Yoon JH, Ryu JH: Neutrophil pyroptosis mediates pathology of $P$. aeruginosa lung infection in the absence of the NADPH oxidase NOX2. Mucosal Immunol 2016, DOI: 10.1038/mi.2016.73.

77 Wolbeling F, Munder A, Kerber-Momot T, Neumann D, Hennig C, Hansen G, Tummler B, Baumann U: Lung function and inflammation during murine Pseudomonas aeruginosa airway infection. Immunobiology 2011;216: 901-908.

78 Gilroy D, De Maeyer R: New insights into the resolution of inflammation. Semin Immunol 2015;27:161-168.

79 Damlund DS, Christophersen L, Jensen PO, Alhede M, Hoiby N, Moser C: Activation of pulmonary and lymph node dendritic cells during chronic Pseudomonas aeruginosa lung infection in mice. APMIS 2016;124:500-507.

80 Ding FM, Zhu SL, Shen C, Ji XL, Zhou X: Regulatory $\mathrm{T}$ cell activity is partly inhibited in a mouse model of chronic Pseudomonas aeruginosa lung infection. Exp Lung Res 2015;41: 44-55.

81 Yan Z, Stewart ZA, Sinn PL, Olsen JC, Hu J, McCray Jr PB, Engelhardt JF: Ferret and pig models of cystic fibrosis: prospects and promise for gene therapy. Hum Gene Ther Clin Dev 2014;26:38-49.

82 Gangell C, Gard S, Douglas T, Park J, de Klerk N, Keil T, Brennan S, Ranganathan S, RobinsBrowne R, Sly PD, Arest CF: Inflammatory responses to individual microorganisms in the lungs of children with cystic fibrosis. Clin Infect Dis 2011;53:425-432.

83 Stoltz DA, Meyerholz DK, Pezzulo AA, Ramachandran S, Rogan MP, Davis GJ, Hanfland RA, Wohlford-Lenane C, Dohrn CL, Bartlett JA, Nelson GAt, Chang EH, Taft PJ, Ludwig PS, Estin M, Hornick EE, Launspach JL, Samuel M, Rokhlina T, Karp PH, Ostedgaard LS, Uc A, Starner TD, Horswill AR, Brogden KA, Prather RS, Richter SS, Shilyansky J, McCray PB Jr, Zabner J, Welsh MJ: Cystic fibrosis pigs develop lung disease and exhibit defective bacterial eradication at birth. Sci Transl Med 2010;2:29ra31.

84 Bruscia EM, Bonfield TL: Innate and adaptive immunity in cystic fibrosis. Clin Chest Med 2016;37:17-29.

85 Winter SE, Baumler AJ: Dysbiosis in the inflamed intestine: chance favors the prepared microbe. Gut Microbes 2014;5:71-73.

86 Marvig RL, Damkiaer S, Khademi SM, Markussen TM, Molin S, Jelsbak L: Withinhost evolution of Pseudomonas aeruginosa reveals adaptation toward iron acquisition from hemoglobin. MBio 2014;5:e00966-e00914.

87 Reid DW, Carroll V, O'May C, Champion A, Kirov SM: Increased airway iron as a potential factor in the persistence of Pseudomonas aeruginosa infection in cystic fibrosis. Eur Respir J 2007;30:286-292.
88 Yu S, Wei Q, Zhao T, Guo Y, Ma LZ: A novel survival strategy of Pseudomonas aeruginosa: using exopolysaccharides to sequester and store iron to stimulate Psl-dependent biofilm formation. Appl Environ Microbiol 2016, DOI: 10.1128/AEM.01307-16.

89 Folsom JP, Richards L, Pitts B, Roe F, Ehrlich GD, Parker A, Mazurie A, Stewart PS: Physiology of Pseudomonas aeruginosa in biofilms as revealed by transcriptome analysis. BMC Microbiol 2010;10:294.

90 Kragh KN, Alhede M, Jensen PO, Moser C, Scheike T, Jacobsen CS, Seier Poulsen S, Eickhardt-Sorensen SR, Trostrup H, Christoffersen L, Hougen HP, Rickelt LF, Kuhl M, Hoiby N, Bjarnsholt T: Polymorphonuclear leukocytes restrict growth of Pseudomonas aeruginosa in the lungs of cystic fibrosis patients. Infect Immun 2014;82:4477-4486.

91 Yoon SS, Hennigan RF, Hilliard GM, Ochsner UA, Parvatiyar K, Kamani MC, Allen HL, DeKievit TR, Gardner PR, Schwab U, Rowe JJ, Iglewski BH, McDermott TR, Mason RP, Wozniak DJ, Hancock RE, Parsek MR, Noah TL, Boucher RC, Hassett DJ: Pseudomonas aeruginosa anaerobic respiration in biofilms: relationships to cystic fibrosis pathogenesis. Dev Cell 2002;3:593-603.

92 Quinn RA, Lim YW, Maughan H, Conrad D, Rohwer F, Whiteson KL: Biogeochemical forces shape the composition and physiology of polymicrobial communities in the cystic fibrosis lung. MBio 2014;5:e00956-e00913.

93 Kolpen M, Bjarnsholt T, Moser C, Hansen CR, Rickelt LF, Kuhl M, Hempel C, Pressler T, Hoiby N, Jensen PO: Nitric oxide production by polymorphonuclear leucocytes in infected cystic fibrosis sputum consumes oxygen. Clin Exp Immunol 2014;177:310-319.

94 Ernst RK, Hajjar AM, Tsai JH, Moskowitz SM, Wilson CB, Miller SI: Pseudomonas aeruginosa lipid A diversity and its recognition by Toll-like receptor 4. J Endotoxin Res 2003;9: 395-400.

95 Ernst RK, Moskowitz SM, Emerson JC, Kraig GM, Adams KN, Harvey MD, Ramsey B, Speert DP, Burns JL, Miller SI: Unique lipid A modifications in Pseudomonas aeruginosa isolated from the airways of patients with cystic fibrosis. J Infect Dis 2007;196:1088-1092.

96 LaFayette SL, Houle D, Beaudoin T, Wojewodka G, Radzioch D, Hoffman LR, Burns JL, Dandekar AA, Smalley NE, Chandler JR, Zlosnik JE, Speert DP, Bernier J, Matouk E, Brochiero E, Rousseau S, Nguyen D: Cystic fibrosis-adapted Pseudomonas aeruginosa quorum sensing lasR mutants cause hyperinflammatory responses. Sci Adv 2015;1: e1500199.

97 Winstanley C, O’Brien S, Brockhurst MA: Pseudomonas aeruginosa evolutionary adaptation and diversification in cystic fibrosis chronic lung infections. Trends Microbiol 2016;24:327-337. 
98 Jorth P, Staudinger BJ, Wu X, Hisert KB, Hayden H, Garudathri J, Harding CL, Radey MC, Rezayat A, Bautista G, Berrington WR, Goddard AF, Zheng C, Angermeyer A, Brittnacher MJ, Kitzman J, Shendure J, Fligner CL, Mittler J, Aitken ML, Manoil C, Bruce JE, Yahr TL, Singh PK: Regional isolation drives bacterial diversification within cystic fibrosis lungs. Cell Host Microbe 2015;18:307-319.

99 Sommer LM, Marvig RL, Lujan A, Koza A, Pressler T, Molin S, Johansen HK: Is genotyping of single isolates sufficient for population structure analysis of Pseudomonas aeruginosa in cystic fibrosis airways? BMC Genomics 2016;17:589.

100 Legssyer R, Huaux F, Lebacq J, Delos M, Marbaix E, Lebecque P, Lison D, Scholte BJ, Wallemacq P, Leal T: Azithromycin reduces spontaneous and induced inflammation in DeltaF508 cystic fibrosis mice. Respir Res 2006;7:134.

101 Konstan MW, Doring G, Heltshe SL, Lands LC, Hilliard KA, Koker P, Bhattacharya S, Staab A, Hamilton A; Investigators and Co- ordinators of BI Trial 543.45: A randomized double blind, placebo controlled phase 2 trial of BIIL 284 BS (an LTB4 receptor antagonist) for the treatment of lung disease in children and adults with cystic fibrosis. J Cyst Fibros 2014;13:148-155.

102 Doring G, Bragonzi A, Paroni M, Akturk FF, Cigana C, Schmidt A, Gilpin D, Heyder S, Born T, Smaczny C, Kohlhaufl M, Wagner TO, Loebinger MR, Bilton D, Tunney MM, Elborn JS, Pier GB, Konstan MW, Ulrich M: BIIL 284 reduces neutrophil numbers but increases $P$. aeruginosa bacteremia and inflammation in mouse lungs. J Cyst Fibros 2014;13:156-163.

103 Shindo Y, Fuchs AG, Davis CG, Eitas T, Unsinger J, Burnham CD, Green JM, Morre M, Bochicchio GV, Hotchkiss RS: Interleukin 7 immunotherapy improves host immunity and survival in a two-hit model of Pseudomonas aeruginosa pneumonia. J Leukoc Biol 2016, DOI: $10.1189 / \mathrm{jlb} .4 \mathrm{~A} 1215-581 \mathrm{R}$.

104 Loberto N, Tebon M, Lampronti I, Marchetti N, Aureli M, Bassi R, Giri MG, Bezzerri V, Lovato V, Cantu C, Munari S, Cheng SH,
Cavazzini A, Gambari R, Sonnino S, Cabrini G, Dechecchi MC: GBA2-encoded beta-glucosidase activity is involved in the inflammatory response to Pseudomonas aeruginosa. PLoS One 2014;9:e104763.

105 Dechecchi MC, Nicolis E, Mazzi P, Cioffi F, Bezzerri V, Lampronti I, Huang S, Wiszniewski L, Gambari R, Scupoli MT, Berton G, Cabrini G: Modulators of sphingolipid metabolism reduce lung inflammation. Am J Respir Cell Mol Biol 2011;45:825-833.

106 Nakamura S, Iwanaga N, Seki M, Fukudome K, Oshima K, Miyazaki T, Izumikawa K, Yanagihara K, Miyazaki Y, Mukae H, Kohno S: Toll-like receptor 4 agonistic antibody promotes host defense against chronic $P$ seudomonas aeruginosa lung infection in mice. Infect Immun 2016;84:1986-1993.

107 Hackstein H, Lippitsch A, Krug P, Schevtschenko I, Kranz S, Hecker M, Dietert K, Gruber AD, Bein G, Brendel C, Baal N: Prospectively defined murine mesenchymal stem cells inhibit Klebsiella pneumoniae-induced acute lung injury and improve pneumonia survival. Respir Res 2015;16:123. 